\title{
Short-term impact of the EuroPean Accredited Curriculum on Tobacco Treatment Training (EPACTT) program
}

\author{
Theodosia Peleki',2, Charis Girvalaki3,2, Francisco Lozano², Cornel Radu-Loghin², Dominick Nguyen², Arusyak Harutyu- \\ nyan ${ }^{4}$, George Bakhturidze ${ }^{5}$, Antigona Trofor ${ }^{6}$, Andrey Deminn ${ }^{7}$, Otto Stoyka ${ }^{8}$, Chrysoula Tsiou ${ }^{9}$, Sophia Papadakis ${ }^{10}$, \\ Constantine I. Vardavas ${ }^{2,11}$, Panagiotis K. Behrakis ${ }^{12,13}$
}

\section{ABSTRACT}

INTRODUCTION The aim of this pilot study was to assess the short-term effectiveness of the EuroPean Accredited Curriculum on Tobacco Treatment Training intervention in improving health care providers' knowledge, attitudes and self-efficacy related to tobacco dependence treatment.

METHOdS A pre-post pilot study was conducted. The two-day training intervention took place in Brussels in April 2016. Health care professionals from six European countries (Russia, Ukraine, Georgia, Armenia, Romania and Greece) were purposively invited to participate in the study. Evaluation was performed before the intervention, immediately after, and at approximately two months following the intervention. Changes in outcomes of interest were examined before and after exposure to the intervention program.

RESULTS In all, 47 health care professionals participated in the training of which 40 completed the evaluation surveys. Significant increases in providers' self-efficacy and perceived behavioral control related to tobacco treatment delivery were documented immediately following the training and at the 2 months follow-up. Significant improvement in provider knowledge and attitudes were observed in some items assessed.

CONCLUSIONS The results demonstrate that training is able to improve provider self-efficacy related to tobacco treatment delivery in this crossnational European sample of health care professionals. Additional research is required to examine the generalizability of our findings.

\section{INTRODUCTION}

Smoking is one of the leading preventable causes of death worldwide ${ }^{1}$. More than 0.7 million Europeans die prematurely as a result of smokingrelated illnesses each year ${ }^{2}$. The European Commissions' latest Special Eurobarometer reported that $46.0 \%$ of tobacco users in Europe have never tried to quit smoking and only $15.0 \%$ of current tobacco users reported having made a quit attempt during the past year ${ }^{3}$. Among those who have attempted to quit smoking, the majority (75\%) reported they did so unassisted $^{3}$. Only a small percentage of those who quit unassisted will maintain long-term abstinence from smoking ${ }^{4-6}$. As a chronic relapsing condition, tobacco dependence treatment is difficult and multi-factorial ${ }^{7,8}$.

Health care professionals have an important role to play in the delivery
AFFILIATION

1 National and Kapodistrian University of Athens, School of Health Sciences, Department of Medicine, Athens, Greece 2 European Network for Smoking and Tobacco Prevention (ENSP), Brussels, Belgium 3 Clinic of Social and Family Medicine, Medical School, University of Crete, Heraklion, Greece

4 School of Public Health, American University of Armenia, Armenia 5 FCTC Implementation and Monitoring Center, Georgia

6 University of Medicine and Pharmacy 'Grigore T.Popa', lasi, Romania

7 Federal State Funded Educational Institution of Higher Education I.M. Sechenov First Moscow State Medical University under the Ministry of Health of the Russian Federation, Russia

8 Kyiv City Health Center, Ukraine

9 Technological Educational Institute of Athens, Greece

10 Division of Prevention and Rehabilitation, University of Ottawa Heart Institute, Ottawa, ON, Canada

11 Institute of Public Health, American College of Greece, George D Behrakis Research Lab, Hellenic Cancer Society, Athens, Greece

12 Institute of Public Health, American College of Greece, Athens, Greece

13 George D Behrakis Research Lab, Hellenic Cancer Society, Biomedical Research Foundation of the Academy of Athens, Athens, Greece

\section{CORRESPONDENCE TO}

Theodosia Peleki. National and Kapodistrian University of Athens, School of Health Sciences, Department of Medicine, Greece, 77 Propontidos, 16562 Athens, Greece. E-mail: sissi@tobcontrol.eu

\section{KEYWORDS}

smoking cessation, training, evidencebased practice, health care professionals, knowledge, attitudes

Received: 22 December 2017

Revised: 20 June 2018

Accepted: 21 June 2018 
of tobacco treatment interventions ${ }^{2,4,9}$. There is strong evidence that the combination of clinician's advice to quit smoking, pharmacotherapy and behavioral counseling can increase success with long-term abstinence three- to six-fold ${ }^{4,9-11}$. In this context, both the World Health Organization and the European Network for Smoking and Tobacco Prevention (ENSP) have identified tobacco dependence treatment as a clinical priority for all healthcare professionals and recommend that all health care providers be trained in evidence-based tobacco treatment delivery and be prepared to intervene with tobacco users in their practice $^{2,9,12,13}$. Despite the importance of this area of clinical practice, the vast majority of clinicians in Europe have not received training in tobacco treatment delivery ${ }^{14}$. Continuing medical education has proven to be effective in changing health care professionals' behaviors in integrating tobacco treatment delivery into daily clinical practice and increasing patient success with quitting ${ }^{15-17}$.

Similar interventions in terms of the content and the tools used have been performed in the past. The 'Ottawa Model for Smoking Cessation' (OMSG), is a multi-component intervention for addressing tobacco use with smokers in primary care settings in Canada. Its evaluation has demonstrated significant improvements in the rates at which evidence-based tobacco treatment is delivered to patients ${ }^{17,18}$, while TiTAN Crete is a European study that adapted the OMSC program for use in primary care settings and developed a network of trained general practitioners (GPs) in Crete, Greece, to integrate treatment of tobacco dependence into daily clinical practice. The results of TiTAN Crete demonstrated that the training intervention was effective in improving a GP's knowledge, self-efficacy and delivery of the 4As (ask, advise, assist, arrange) tobacco treatment ${ }^{19}$.

The aim of this study was to assess the short-term effectiveness of the EuroPean Accredited Curriculum on Tobacco Treatment Training intervention in improving health care provider's knowledge, attitudes and self-efficacy related to tobacco dependence treatment.

\section{METHODS}

A pre-post pilot study was conducted. This study was undertaken as part the EuroPean Accredited
Curriculum on Tobacco Treatment (EPACTT) project. The purpose of EPACTT was to create and mobilize a network of healthcare professionals, dedicated to advancing evidence-based tobacco dependence treatment and advocating for effective tobacco control policy in the Eastern European Region with specific focus on clinician and policy makers in Russia, Ukraine, Georgia, Armenia and Romania.

The training intervention was held in Brussels, Belgium in April 2016. Participants were asked to complete an online study questionnaire at three time points, before the intervention (T1-March 2016), immediately after (T2-April 2016) and two months following the training (T3-June 2016).

\section{Recruitment}

A convenience sample of health care professionals was recruited from the six participating European countries (Russia, Ukraine, Georgia, Armenia, Romania and Greece). The lead representatives from each country were asked to identify a list of ten health care professionals to participate in the pilot study. Eligibility criteria included: 1) being a health care professional (i.e. general practitioners, nurses, midwives, psychologists, social workers, pharmacists); 2) ability to read and comprehend English; 3) currently working with smokers on a daily basis; and 4) able to participate in the training event in Brussels. Each of the identified health care professionals received an information letter and an invitation to participate via email with a link to the baseline survey. All healthcare professionals were required to provide informed consent and completed the baseline survey. Participants also completed a printed survey at the end of the second day of the training. Two months following the training, participants were contacted via email with a link to the follow-up survey. Three email reminders were sent over a three-week period before categorizing the participant as loss to follow-up.

\section{Intervention and evaluation framework}

The training intervention and evaluation design was informed by behavioral theory and existing research, in terms of the process by which training interventions are thought to influence provider behaviors $^{20,21}$. Specifically, we sought to influence provider's knowledge, attitudes and confidence (self- 
efficacy) related to the delivery of evidence-based tobacco treatment ${ }^{22,23}$. We also evaluated social norms in terms of the importance of tobacco control within clinical practice. Each of the areas targeted have been identified in the literature as barriers to tobacco treatment delivery ${ }^{22,25,26}$.

\section{Training intervention}

The intervention was based on the 2015 European Tobacco Treatment Guidelines published by the European Network for Smoking and Tobacco Prevention (ENSP) and was designed to meet multidisciplinary needs and to provide knowledge and skills to support the integration of evidencebased tobacco treatment into daily clinical practice ${ }^{13}$. The two-day training program was delivered by tobacco treatment experts who were involved in the development of the ENSP clinical practice guidelines. The training program covered the following learning areas: 1) data on the tobacco epidemic in Europe, 2) health effects of tobacco use, 3) pathophysiology of addiction to nicotine, 4 ) the role of health care professionals in tobacco control, 5 ) evidence-based practices for tobacco treatment delivery including counseling techniques and pharmacotherapy, 6) tobacco control legislation and enforcement on an international and European level, and 7) standards for the establishment and operation of a smoking cessation clinic. Active learning methods such as teaching role-play and case studies were used as part of the training intervention.

\section{Evaluation tool}

The baseline study survey collected information about the demographics of health professionals, such as gender, age, smoking status, number of years practicing as well as previous training in smoking cessation. At time points T1, T2 and T3 we assessed provider knowledge (12 items), attitudes (10 items), perceived behavioral control ( 5 items), and self-efficacy ( 6 items) related to tobacco treatment delivery. All knowledge questions were based on the 2015 European Network on Smoking Cessation Guidelines ${ }^{13}$. The survey instrument was originally a modification of an existing tool developed by Papadakis et al. ${ }^{22,23}$, and builds on the work of Delucchi and others ${ }^{24,27}$. The survey instrument was adapted for use in European health care settings.

\section{Statistical analysis}

Frequencies and percentages were used to summarize demographic characteristics of the sample and outcomes variables at time points T1, T2 and T3. Data reported on a 5 -point Likert scale ( $1=$ strongly disagree, $2=$ disagree, $3=$ neutral, $4=$ agree, $5=$ strongly agree) were recoded as follows: strongly disagree and disagree $=$ disagree; neutral $=$ neutral; strongly agree and agree $=$ agree. Chi-squared tests were performed to evaluate the effectiveness of the intervention in improving health care professionals' knowledge, attitudes, perceived behavioral control, self-efficacy (a 10-point Likert scale was used with $1=$ not very confident to $10=$ extremely confident) before and immediately after the intervention ( $\mathrm{T} 1 \mathrm{vs} \mathrm{T} 2$ ) and at 2 months following the intervention (T1 vs T3). For the analysis of continuous data, we performed Kolmogorov-Smirnov test to check for the normality of our data and analysis of variance (ANOVA) was performed. Statistical significance was set at 0.05 . Only those health care professionals $(n=40)$ who completed the training and follow-up surveys were included in the final analysis. Missing data were not imputed. Statistical analysis was performed using the Statistical Package for Social Sciences (SPSS, 21st Edition).

\section{RESULTS}

The recruitment flow diagram is presented as Figure 1. A total of 68 health care professionals consented to participate in the study, of which 47 attended the training intervention while 7 were lost to followup (69.1\% retention rate). The primary reason for withdrawal from the study was inability to travel to the training event. It should be noted that the week prior to the training event a terrorist attack occurred in Paris, which resulted in many participants canceling their travel.

Supplementary Table 1 depicts the demographic and descriptive characteristics of the study participants. The majority $(77.5 \%)$ of participants were women and $40 \%$ of the sample worked in a hospital. Participants had been practicing for an average of $21.4(\mathrm{SD}=24.2)$ years. The majority of the sample $(62.5 \%)$ had not previously participated in training on smoking cessation.

Increases were documented in 11 of the 12 knowledge areas assessed immediately following the training, with significant increases 
Figure 1. Recruitment Flow Diagram

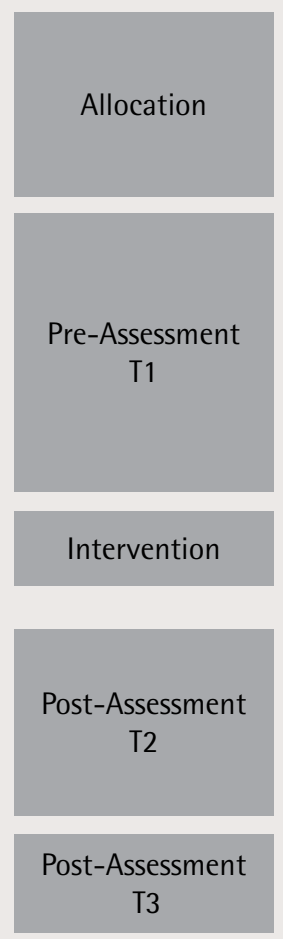

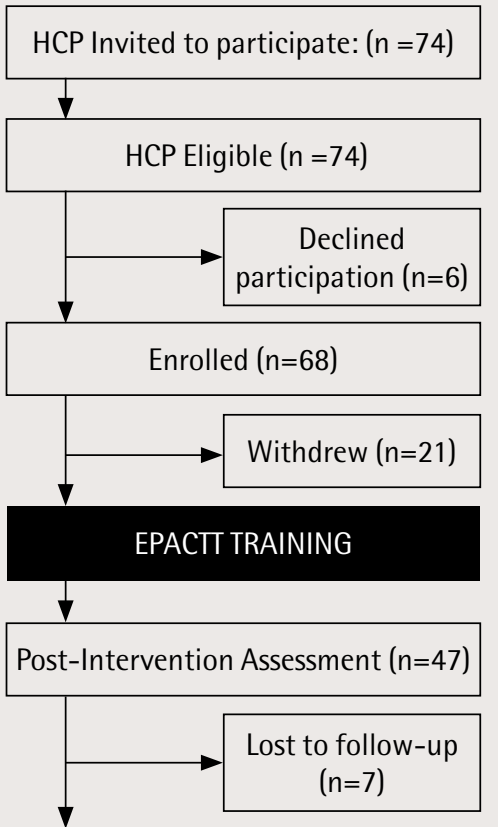

2 Months Follow-up Assessment $(n=40)$

documented in 3 of the 12 areas assessed: pharmacotherapy effectiveness $(5.1 \%$ at $\mathrm{T} 1 \mathrm{vs} 70 \%$ at $\mathrm{T} 2, \mathrm{p}<0.001)$; craving duration $(41.0 \%$ at $\mathrm{T} 1$ vs $72.5 \%$ at $\mathrm{T} 2, \mathrm{p}=0.005)$; relapse reason $(66.7 \%$ at $\mathrm{T} 1$ vs $87.5 \%$ $\mathrm{T} 2, \mathrm{p}=0.027$ ) (Table 1). For three of the knowledge areas less than $50 \%$ of participants responded correctly. Comparisons between the assessment before training (T1) and at the 2 months follow-up (T3) indicate that knowledge was not retained by all participants: pharmacotherapy effectiveness $(5.1 \%$ at $\mathrm{T} 1 \mathrm{vs} 59 \%$ at $\mathrm{T} 3, \mathrm{p}<0.001)$; craving duration $(41.0 \%$ at $\mathrm{T} 1$ vs $59 \%$ at $\mathrm{T} 3, \mathrm{p}=0.113)$; relapse reason $(66.7 \%$ at $\mathrm{T} 1 \mathrm{vs} 69.2 \%$ at $\mathrm{T} 3, \mathrm{p}=0.808$ )

Positive changes in most items assessing provider attitudes related to tobacco treatment delivery significantly increased between the pre-assessment (T1) and immediately after the intervention (T2), however significant increases were observed in only 2 of the 10 items assessed: smoking cessation follow up ( $\mathrm{T} 1 \mathrm{vs} \mathrm{T} 2, \mathrm{p}=0.032$; $\mathrm{T} 1 \mathrm{vs} \mathrm{T} 3, \mathrm{p}=0.022$ ); pharmacotherapy effectiveness ( $\mathrm{T} 1 \mathrm{vs} \mathrm{T} 2, \mathrm{p}<0.001$; T1 vs T3, p=0.023) (Table 2).

Table 1. Changes in health care professionals' tobacco treatment knowledge after the training intervention, Brussels, Belgium (n=40)

\begin{tabular}{|c|c|c|c|c|c|c|c|}
\hline Knowledge area & $\begin{array}{c}\text { TI } \\
\text { Pre } \\
\%(n)\end{array}$ & $\begin{array}{l}\text { T2 } \\
\text { Post } \\
\%(n)\end{array}$ & $\begin{array}{l}\text { TI v: } \\
\text { Change } \\
\%\end{array}$ & T2 & $\begin{array}{c}\text { T3 } \\
\text { At } 2 \text { months } \\
\text { follow-up } \%(\mathrm{n})\end{array}$ & Change & s T3 \\
\hline $\begin{array}{l}\text { Are electronic cigarettes effective in helping people to } \\
\text { quit smoking }\end{array}$ & $66.7(26)$ & $70.0(28)$ & +3.3 & 0.750 & 74.4 (29) & +7.7 & 0.456 \\
\hline $\begin{array}{l}\text { It is safe to continue to smoke while using nicotine } \\
\text { replacement therapies (NRTs) }\end{array}$ & $35.9(14)$ & $30.0(12)$ & -5.9 & 0.577 & $43.6(17)$ & +7.7 & 0.488 \\
\hline $\begin{array}{l}\text { Which are the most effective medications in terms of } \\
\text { increase success rates }\end{array}$ & $5.1(2)$ & $70.0(28)$ & +64.9 & $<0.001$ & $59.0(23)$ & +53.9 & $<0.001$ \\
\hline How long does a typical craving last? & $41.0(16)$ & $72.5(29)$ & +31.5 & 0.005 & $59.0(23)$ & +18 & 0.113 \\
\hline Which is the most common side effect of varenicline? & $56.4(22)$ & $76.9(30)$ & +20.5 & 0.055 & $64.1(25)$ & +7.7 & 0.488 \\
\hline $\begin{array}{l}\text { People who quit smoking will have more, less, or the } \\
\text { same amount of stress? }\end{array}$ & $35.9(14)$ & $37.5(15)$ & +1.6 & 0.883 & $48.7(19)$ & +12.8 & 0.252 \\
\hline It is more difficult for women who are pregnant to quit smoking? & $33.3(13)$ & $42.5(17)$ & +9.2 & 0.401 & $43.6(17)$ & +10.3 & 0.352 \\
\hline $\begin{array}{l}\text { What are the most common reasons that people return to } \\
\text { smoking in the first few weeks after quitting? }\end{array}$ & $84.6(33)$ & $92.5(37)$ & +7.9 & 0.270 & 74.4 (29) & -10.2 & 0.262 \\
\hline $\begin{array}{l}\text { What are the most common reasons people return to } \\
\text { smoking in the long term? }\end{array}$ & $66.7(26)$ & $87.5(35)$ & +20.8 & 0.027 & $69.2(27)$ & +2.5 & 0.808 \\
\hline $\begin{array}{l}\text { A physician's advice to quit smoking can boost } \\
\text { motivation to quit by what } \% \text { ? }\end{array}$ & $38.5(15)$ & $55.0(22)$ & +16.5 & 0.141 & $56.4(22)$ & +17.9 & 0.112 \\
\hline $\begin{array}{l}\text { Nicotine replacement therapies are contraindicated in } \\
\text { individuals with cardiovascular disease? }\end{array}$ & $66.7(26)$ & $77.5(31)$ & +10.8 & 0.283 & $84.6(33)$ & +17.9 & 0.065 \\
\hline Is nicotine as addictive as other drugs such as heroin or cocaine? & $87.2(34)$ & $97.4(38)$ & +10.2 & 0.089 & $92.3(36)$ & +5.1 & 0.455 \\
\hline $\begin{array}{l}\text { With brief counseling by a physician and use of } \\
\text { pharmacotherapies approximately how many people } \\
\text { are expected to quit smoking? }\end{array}$ & $38.5(15)$ & $40.0(16)$ & +1.5 & 0.889 & $15.4(6)$ & -23.1 & 0.022 \\
\hline
\end{tabular}


Table 2. Changes in tobacco related attitudes and perceived behavioral control among participants before, immediately after, and at 2 months following exposure to the training intervention, Brussels, Belgium (n=-

\author{
10)
}

\begin{tabular}{|c|c|c|c|c|c|}
\hline & $T 1$ & $T 2$ & TI vs T2 & T3 & T1 vs T3 \\
\hline Variable & $\begin{array}{l}\text { Pre } \\
{ }_{0}(n)\end{array}$ & $\begin{array}{l}\text { Post } \\
\%(n)\end{array}$ & p & $\begin{array}{c}\text { At } 2 \text { mont lis } \\
\text { follow up } \\
\% \text { (n) }\end{array}$ & p \\
\hline
\end{tabular}

\title{
Attitudes
}

Helping my patients quit smoking is an important part of my role as a clinician

Disagree

$\begin{array}{ccccc}0.0(0) & 0.0(0) & 0.221 & 2.7(1) & \\ 17.9(7) & 8.3(3) & & 10.8(4) & 0.413 \\ 82.1(32) & 91.7(33) & & 86.5(32) & \end{array}$

Agree*

Clinicians should advise patients to quit smoking even if it's not the reason for the visit

Disagree
Neutral
Agree*
Counseling by a clinician helps motivate smokers to quit
Disagree
Neutral
Agree*
Clinicians should make appointments specifically to help patients quit
Disagree

Neutral

Agree *

$\begin{array}{cc}2.8(1) & 2.6(1) \\ 13.9(5) & 2.6(1) \\ 83.3(30) & 94.7(36)\end{array}$

0.206

$\begin{array}{ccccc}8.3(3) & 0.0(0) & & 0.0(0) & \\ 13.9(5) & 5.3(2) & 0.073 & 5.4(2) & 0.080 \\ 77.8(28) & 94.7(36) & & 94.6(35) & \end{array}$

Smoking is a personal decision that does not concern the clinician

Disagree *

Neutral

$\begin{array}{ccccc}0.0(0) & 2.6(1) & & 5.3(2) & \\ 30.6(11) & 7.9(3) & 0.032 & 7.9(3) & 0.022 \\ 69.4(22) & 89.5(34) & & 86.8(33) & \end{array}$

Agree

For many tobacco users smoking is an addiction

Disagree

$\begin{array}{lcccc}60.5(23) & 60.5(23) & 0.934 & 84.2(32) & \\ 18.4(7) & 15.8(6) & & 7.9(3) & 0.069 \\ 21.1(8) & 23.7(9) & & 7.9(3) & \\ & & & & \\ 3.0(1) & 10.5(4) & & 5.6(2) & \\ 24.2(8) & 10.5(4) & 0.177 & 8.3(3) & 0.185 \\ 72.7(24) & 78.9(30) & & 86.1(31) & \end{array}$

Agree *

A patient's will power alone is what will determine their success with quitting

Disagree *

$\begin{array}{llll}31.0(9) & 50.0(19) & 0.102 & 50.0(19) \\ 41.4(12) & 18.4(7) & & 28.9(11) \\ 27.6(8) & 31.6(12) & & 21.1(8)\end{array}$

0.294

Neutral

Agree

First line pharmacotherapies for smoking cessation work well in helping patients quit

Disagree

$\begin{array}{cccc}0.0(0) & 7.9(3) & <0.001 & 2.6(1) \\ 48.4(15) & 5.3(2) & & 18.4(7) \\ 51.6(16) & 86.8(33) & & 78.9(30)\end{array}$

0.023

Agree*

First line pharmacotherapies for smoking cessation are not safe, have side effects that out weight their benefits

Disagree *

$\begin{array}{ccccc}55.6(20) & 60.5(23) & 0.121 & 13.2(5) & 0.103 \\ 36.1(13) & 18.4(7) & & 18.4(7) & \\ 8.3(3) & 21.1(8) & & 68.4(26) & \\ & & & & \\ 0.0(0) & 8.3(3) & & 5.3(2) & 0.327 \\ 21.9(7) & 16.7(6) & 0.231 & 18.4(7) & \\ 78.1(25) & 75.0(27) & & 55.3(21) & \end{array}$

Agree

It is my usual practice to assist my patients to quit smoking

Disagree

Neutral

Agree*

$78.1(25) \quad 75.0(27)$ 
Table 2. Continued

\begin{tabular}{|c|c|c|c|c|c|}
\hline & TI & $T 2$ & T1 vs T2 & T3 & TI vs T3 \\
\hline Variable & $\begin{array}{l}\text { Pre } \\
\%(n)\end{array}$ & $\begin{array}{l}\text { Post } \\
\%(n)\end{array}$ & $p$ & $\begin{array}{c}\text { Al } 2 \text { months } \\
\text { follow-up } \\
\%(n)\end{array}$ & $p$ \\
\hline \multicolumn{6}{|c|}{ I have the required skills to help my patients quit smoking } \\
\hline Disagree & $0.0(0)$ & $0.0(0)$ & 0.003 & $2.6(1)$ & \\
\hline Neutral & $38.7(12)$ & $8.3(3)$ & & $13.2(5)$ & 0.038 \\
\hline Agree $^{*}$ & $61.3(19)$ & $91.7(17)$ & & $84.2(32)$ & \\
\hline \multicolumn{6}{|c|}{ My patients follow my advice about behavior change smoking } \\
\hline Disagree & $0.0(0)$ & $0.0(0)$ & 0.005 & $5.3(2)$ & \\
\hline Neutral & $48.5(16)$ & $16.7(6)$ & & $26.3(10)$ & 0.085 \\
\hline Agree $^{*}$ & $51.5(17)$ & $83.3(30)$ & & $68.4(26)$ & \\
\hline \multicolumn{6}{|c|}{ My patients who smoke want to quit smoking } \\
\hline Disagree & $2.8(1)$ & $5.6(2)$ & & $7.9(3)$ & \\
\hline Neutral & $66.7(24)$ & $36.1(13)$ & 0.035 & $28.9(11)$ & 0.005 \\
\hline Agree $^{*}$ & $30.6(11)$ & $58.3(21)$ & & $63.2(24)$ & \\
\hline \multicolumn{6}{|c|}{ I do not feel I have an effective method to assist my patients with quitting } \\
\hline Disagree $^{*}$ & $28.6(10)$ & $67.6(25)$ & $<0.001$ & $57.9(22)$ & 0.028 \\
\hline Neutral & $54.3(19)$ & $13.5(5)$ & & $26.3(10)$ & \\
\hline Agree & $17.1(6)$ & $18.9(7)$ & & $15.8(6)$ & \\
\hline \multicolumn{6}{|c|}{ I know where to refer patients for help with smoking cessation } \\
\hline Disagree & $15.4(6)$ & $16.2(6)$ & 0.003 & $13.2(5)$ & 0.010 \\
\hline Neutral & $48.7(19)$ & $13.5(5)$ & & $18.4(7)$ & \\
\hline Agree $^{*}$ & $35.9(14)$ & $70.3(26)$ & & $68.4(26)$ & \\
\hline
\end{tabular}

Responses provided using a 5-point Likert scale ( $1=$ strongly disagree, $2=$ disagree, $3=$ neutral, $4=$ agree, $5=$ strongly agree) .

Responses recoded as: strongly disagree and disagree $=$ disagree; strongly agree and agree $=$ agree. ${ }^{*}$ indicates correct response

Significant increases were documented in $\mathrm{T} 1 \mathrm{vs} \mathrm{T} 3, \mathrm{p}=0.010$ ) (Table 2). Immediately after all of the perceived behavioral control items assessed at the end of training: smoking cessation skills ( $\mathrm{T} 1 \mathrm{vs} \mathrm{T} 2, \mathrm{p}=0.003$; $\mathrm{T} 1 \mathrm{vs} \mathrm{T} 3, \mathrm{p}=0.038$ ); patient compliance ( $\mathrm{T} 1$ vs $\mathrm{T} 2, \mathrm{p}=0.005 ; \mathrm{T} 1$ vs T3, p=0.085); desire to quit smoking ( $\mathrm{T} 1$ vs $\mathrm{T} 2, \mathrm{p}=0.035$; $\mathrm{T} 1$ vs $\mathrm{T} 3, \mathrm{p}=0.005)$; smoking cessation methods (T1 vs T2, $\mathrm{p}<0.001$; T1 vs T3, $\mathrm{p}=0.028$ ); patient referral ( $\mathrm{T} 1 \mathrm{vs} \mathrm{T} 2, \mathrm{p}=0.003$; the intervention, health care professionals were significantly more confident in their ability to deliver evidence-based tobacco treatment with significant increases observed in all self-efficacy items assessed following training, with the exception of arranging timely follow-up support for patients (Table 3). These changes remained significant at the two months follow-up.

Table 3. Changes in health care professionals' self-efficacy related to tobacco treatment delivery following exposure to the training intervention, Brussels, Belgium (n=40)

\begin{tabular}{|c|c|c|c|c|c|}
\hline & TI & $\mathrm{T} 2$ & T1 vs T2 & T3 & TI vs T3 \\
\hline Variable & $\begin{array}{c}\text { Pre } \\
\text { Mean (SI)) }\end{array}$ & $\begin{array}{l}\text { Post } \\
\text { Mean } \\
\text { (SD) }\end{array}$ & $p$ & $\begin{array}{l}\text { Al } 2 \text { months } \\
\text { follow up } \\
\text { Vean (SD) }\end{array}$ & $p$ \\
\hline Advising patients to quit smoking & $8.37(2.2)$ & $8.69(1.6)$ & 0.040 & $8.97(1.4)$ & $<0.001$ \\
\hline Providing brief smoking cessation counselling ( $<3$ minutes) & $8.13(2.6)$ & $8.64(1.6)$ & $<0.001$ & $8.67(1.9)$ & 0.005 \\
\hline Providing counseling to patients not motivated to quit & $7.24(2.8)$ & $8.10(1.9)$ & $<0.001$ & $8.10(1.8)$ & $<0.001$ \\
\hline Prescribing quit-smoking medications & $6.03(3.5)$ & $7.74(2.7)$ & 0.004 & $7.62(2.5)$ & 0.002 \\
\hline Providing smoking cessation counselling & $7.26(3.0)$ & $8.28(2.0)$ & $<0.001$ & $8.44(1.9)$ & $<0.001$ \\
\hline Arranging timely follow-up for patients planning to quit & $9.32(17.0)$ & $8.51(1.7)$ & 0.098 & $8.23(2.0)$ & 0.105 \\
\hline
\end{tabular}

'On a scale from 1-10, how would you describe your confidence...', responses provided on a 1-10 scale (1=not very confident to $10=$ extremely confident). 


\section{DISCUSSION}

The results of our study showed that an evidencebased training program is effective in significantly increasing health care professionals' confidence in their ability to deliver evidence-based tobacco treatment to their patients who smoke. Following the training, more than $90 \%$ of participants reported that they felt that they had the required skills to help their patients to quit smoking, a significant increase documented relative to baseline (61.3\% vs $91.7 \%$; $\mathrm{p}=0.001$ ).

While there was a significant improvement in self-efficacy in all areas of evidence-based tobacco treatment delivery, the average score for motivating patients not ready to quit smoking and prescribing quit- smoking medications suggests that there is room for further improvement. Importantly, we did not document a significant increase in provider confidence to arrange timely follow-up for patients embarking on a quit attempt. This suggests factors outside the training may influence provider's confidence in their ability to delivery follow-up support to patients. This important finding should be further explored.

While there was an overall increase in provider knowledge documented across the 12 domains assessed, in 4 of the knowledge questions less than $50 \%$ of providers responded correctly at follow-up (T3). While each individual knowledge area may not be critical to tobacco treatment delivery, future training and evaluation work should ensure that critical areas of knowledge are emphasized within the training program to a greater extent.

Positive increases were documented in several of the provider 'attitudes' thought to be associated with the frequency at which health care professionals deliver tobacco treatment following exposure to the training. We did not, however, document significant improvements in all of the provider 'attitudes' assessed. Future research should examine intervention strategies for influencing health care provider attitudes and intentions related to tobacco treatment delivery, which may include tactics in addition to training.

Several studies have indicated that negative attitudes and a lack in both knowledge and confidence in tobacco treatment are common among health care professionals and are barriers to tobacco treatment delivery ${ }^{5,25,28-32}$. In the present study the majority of health care professionals had not previously received training in tobacco treatment, reported low baseline knowledge in several areas assessed, had poor attitudes, and low self-efficacy related to smoking cessation counseling and in prescribing quit-smoking medications. These data support the importance of interventions such as that assessed as part of the EPACTT program.

The results of our study are in agreement with other studies, which reported improved knowledge and skills in counseling for smoking cessation following training ${ }^{33-36}$. A large survey conducted in 2014 at 146 smoking cessation centers showed that both online and face-to-face interventions can effectively improve the knowledge and skills of health care professionals ${ }^{37}$. There is good evidence that health care professionals who receive training on smoking cessation are more likely to deliver smoking cessation counseling, and are more likely to use evidence-based tobacco treatment techniques ${ }^{17,36}$. There was a decline in some of the knowledge domains observed between the post-training and at the 2 months follow-up assessment, which may support the need for additional training over time to maintain tobacco treatment knowledge.

This study is subject to certain methodological limitations. It is unclear whether health care professionals participated in our intervention are representative of the general population, as most of them were members of European organizations for smoking prevention. Our pilot study included a relatively small sample size that may also limit the generalization of the results. The survey instrument was based on existing knowledge of provider behavior change in terms of tobacco treatment delivery, however this is an under-studied area of research and there may be other factors not measured in our study that influence provider behaviors. Given the survey was anonymous and completely voluntary, one can assume that attitudinal variables were reliably captured ${ }^{38}$.

\section{CONCLUSIONS}

The results of this pilot study demonstrate that tobacco treatment training is able to improve health professional's knowledge and self-efficacy related to smoking cessation treatment. Ongoing training 
and other intervention tactics may be necessary to maintain and further improve provider knowledge, attitudes and skills.

\section{REFERENCES}

1. World Health Organization. WHO Fact Sheet for Tobacco. Updated 2016. www.who.int/mediacentre/ factsheets/fs339/en/. Published November, 2016. Accessed April, 2016.

2. World Health Organization. WHO global report: mortality attributable to tobacco. 2012. www.who. int/tobacco/publications/surveillance/rep_mortality_ attributable/en/. Published November, 2016. Accessed April, 2016.

3. European Commission. Special Eurobarometer 458: Attitudes of Europeans towards tobacco and electronic cigarettes. European Commission, 2017. ISBN: 97892-79-69104-1. www.ec.europa.eu/commfrontoffice/ publicopinion/index.cfm/Survey/getSurveyDetail/ instruments/SPECIAL/surveyKy/2146 Published November, 2016. Accessed April, 2016.

4. Fiore MC, Jaen CR, Baker TB, Bailey WC, Benowitz NL, Curry SE, et al. Treating Tobacco Use and Dependence: 2008 Update. Clinical Practice Guideline. Rockville, MD: U.S. Department of Health and Human Services. Public Health Service; 2008.

5. McIvor A, Kayser J, Assaad JM, Brosky G, Demarest $\mathrm{P}$, Desmarais $\mathrm{P}$, et al. Best practices for smoking cessation interventions in primary care. Can Respir J. 2009;16(4):129-34. doi:10.1155/2009/412385

6. Doll R, Peto R, Boreham J, Sutherland I. Mortality in relation to smoking: 50 years' observations on male British doctors. BMJ. 2004; 328(7455): 1519. doi:10.1136/bmj.38142.554479.ae

7. Huddlestone L, Walker GM, Hussain-Mills R, Ratschen E. Treating tobacco dependence in older adults: a survey of primary care clinicians' knowledge, attitudes, and practice. BMC Fam Pract. 2015;16:97. doi: 10.1186/s12875-015-0317-7

8. Centers for Disease Control and Prevention. Adult Tobacco Survey. 19 states, 2003-2007 surveillance summaries. Morb Mortal Wkly Rep 2010; 59: 1-74

9. European Network on Smoking Prevention (ENSP). Behrakis P., Bilir N., Clancy L, Dautzenberg B., Demin, A., Papadakis S., Gilijam H., Trofor A., Vardavas C. (Eds.). 2017 Guidelines for Treating Tobacco Dependence. 3rd ed. European Network for Smoking and Tobacco Prevention (ENSP), Brussels, Belgium 2017. ISBN: 978618-82526-6-0.

10. Stead LF, Buitrago D, Preciado N, Sanchez G, HartmannBoyce J, Lancaster T. Physician advice for smoking cessation. Cochrane Database Syst Rev 2013; 5: CD000165. doi: 10.1002/14651858.CD000165.pub4

11. Stead LF, Koilpillai P, Fanshawe TR, Lancaster T.
Combined pharmacotherapy and behavioural interventions for smoking cessation. Cochrane Database Syst Rev 2016; 3: CD008286. doi: 10.1002/14651858.CD008286.pub3

12. European Network on Smoking Prevention (ENSP). European Smoking Cessation Guidelines. 1st Ed. Brussels, Belgium 2012.

13. European Network on Smoking Prevention (ENSP). Behrakis P., Bilir N., Clancy L, Dautzenberg B., Demin, A., Papadakis S., Gilijam H., Trofor A., Vardavas C. (Eds.). Guidelines for Treating Tobacco Dependence. 2nd Ed. European Network for Smoking and Tobacco Prevention (ENSP), Brussels, Belgium 2015. ISBN: 978618-82526-6-0.

14. La Torre G, Kirch W, Bes-Rastrollo M, Ramos RM, Czaplicki M, Gualano MR, et al. Tobacco use among medical students in Europe: Results of a multicentre study using the Global Health Professions Student Survey. Public Health. 2012; 126(2): 159-64. doi: 10.1016/j.puhe.2011.10.009

15. Mostofian F, Ruban C, Simunovic N, Bhandari M. Changing physician behavior: what works? Am J. Manag Care 2015; 21(1): 75-84. doi:10.1001/jama.2016.8019

16. Carson KV, Verbiest MEA, Crone MR, Brinn MP, Esterman AJ, Assendelft WJJ, Smith BJ. Training health professionals in smoking cessation. Cochrane Database Syst Rev 2012; 5 : CD000214. doi: 10.1002/14651858.CD000214.pub2

17. Papadakis S, McDonald P, Mullen, et al. Strategies to increase the delivery of smoking cessation treatments in primary care settings: A systematic review and metaanalysis. Preventive Medicine 2010; 51: 199-213.

18. Papadakis S, Cole AG, Reid RD, et al. Increasing Rates of Tobacco Treatment Delivery in Primary Care Practice: Evaluation of the Ottawa Model for Smoking Cessation. Ann Fam Med. 2016;14(3):235-243. doi:10.1370/afm.1909.

19. Girvalaki C, Papadakis S, Vardavas C, et al. Training general practitioners in evidence-based tobacco treatment: an evaluation of the Tobacco Treatment Training Network in Crete (TiTANCrete) intervention. Heal Educ Behav. 2018. doi: 10.1177/1090198118775481

20. Bandura A. Health promotion by social cognitive means. Health education and behavior 2004; 31(2): 143-164. doi:10.1177/1090198104263660

21. Ajzen I. Theory of planned behaviour. Organizational Behavior and Human Decision Processes. 1991; 50(2): 179-211. doi: 10.1016/0749-5978(91)90020-t

22. Papadakis, S., Pipe, AL., Reid, RD., Tulloch, H., Mullen K., Assi R., Cole A., Wells, G. Effectiveness of performance coaching for enhancing rates of smoking cessation treatment delivery by primary care providers: Study protocol for a cluster randomized controlled trial. Contemp Clin Trials. 2015 Nov;45(Pt B):184-190. doi: 10.1016/j.cct.2015.08.013

23. Girvalaki C., Papadakis S., Vardavas C., Pipe A., Lionis C. Tobacco treatment Training Network in Crete (TiTAN- 
Crete): protocol for a controlled before-after study. Tob. Prev. Cessation 2016;2(64). doi: 10.18332/tpc/63823

24. Delucchi KL, Tajima B, Guydish J. Development of the smoking knowledge, attitudes, and practices (S-KAP) instrument. J Drug Issues. 2009;39(2):347-364. doi:10.1177/002204260903900207

25. Vogt F, Hall S, Marteau TM. General practitioners' and family physicians' negative beliefs and attitudes towards discussing smoking cessation with patients: a systematic review. Addiction. 2005;100(10):1423-31. doi: 10.1111/j.1360-0443.2005.01221.x

26. Pipe, A.; Sorensen, M.; Reid, R. Physician smoking status, attitudes toward smoking, and cessation advice to patients: An international study. Patient Educ. Couns. 2009;74:118-123. doi:10.1016/j.pec.2008.07.042

27. Ampt AJ, Amoroso C, Harris MF, McKenzie SH, Rose VK, Taggart JR. Attitudes, norms and controls influencing lifestyle risk factor management in general practice. BMC Fam Pract.2009;10(59):2296-10-59. doi: 10.1186/1471-2296-10-59.

28. Eldein HN, Mansour NM, Mohamed SF. Knowledge, Attitude and Practice of Family Physicians Regarding Smoking Cessation Counseling in Family Practice Centers, Suez Canal University, Egypt. J Family Med Prim Care. 2013; 2(2): 159-163. doi: 10.4103/2249-4863.117411.

29. Jiménez-Ruiz C.A, Riesco Miranda J.A, Ramos Pinedo A, de Higes Martinez E, Marquez F.L, Palomo Cobos L, et al. Prevalence of and Attitudes towards Smoking among Spanish Health Professionals. Respiration 2015; 90:474480. doi: 10.1159/000441306.

30. Hjalmarson A, Boëthius G. The effectiveness of brief advice and extended smoking cessation counseling programs when implemented routinely in hospitals. Prev Med. 2007; 45(2-3): 202-7. doi: 10.1016/j.ypmed.2007.06.014

31. De Silva W, Awang R, Samsudeen S, Hanna F. A Randomised Single-Blinded Controlled Trial on the Effectiveness of Brief Advice on Smoking Cessation among Tertiary Students in Malaysia. J Health Med Inform. 2016;7(1). doi: : 10.4172/2161-1459.1000217

32. Luh DL, Chen SL, Yen AM, Chiu SY, Fann CY, Chen HH. Effectiveness of advice from physician and nurse on smoking cessation stage in Taiwanese male smokers attending a community-based integrated screening program. Tob Induc Dis. 2016;23(14). doi: 10.1186/s12971-016-0080-0

33. Matten P, Morrison V, Rutledge DN, Chen T, Chung E, Wong SF. Evaluation of tobacco cessation classes aimed at hospital staff nurses. Oncol Nurs Forum. 2011; 38(1): 67-73. doi: 10.1188/11.ONF.67-73.

34. Walsh MM, Belek M, Prakash P, Grimes B, Heckman B, Kaufman N. The effect of training on the use of tobaccouse cessation guidelines in dental settings. J Am Dent Assoc. 2012; 143(6): 602-13.

35. Kristina SA, Thavorncharoensap M, Pongcharoensuk P, Prabandari YS. Impact of smoking cessation training for community pharmacists in Indonesia. Asian Pac J Cancer Prev. 2015;16(8):3319-23. doi:10.7314/apjcp.2015.16.8.3319

36. Purkabiri K, Steppacher V, Bernardy K, Karl N, Vedder V, Borgmann M, Rogausch A, Stammberger U, Bals R, Raupach T, Koellner V, Hamacher J. Outcome of a four-hour smoking cessation counselling workshop for medical students. Tob Induc Dis. 2016;25:14:37. doi: 10.1186/s12971-016-0103-x

37. Brose LS, West R, Michie S, McEwen A. Changes in success rates of smoking cessation treatment associated with take up of a national evidence based training programme. Prev Med. 2014;69:1-4. doi: 10.1016/j.ypmed.2014.08.021

38. Chan, D. So why ask me? Are self-report data really that bad. Statistical and methodological myths and urban legends: Doctrine, verity and fable in the organizational and social sciences, 2009: 309-336.
CONFLICTS OF INTEREST P. K. Behrakis is the Editor of TPC and there are no conflicts of interest with the current work. The rest of the authors also have completed and submitted an ICMJE form for disclosure of potential conflicts of interest. The authors declare that they have no competing interests, financial or otherwise, related to the current work.

\section{FUNDING}

The EPACTT1 project was supported by Global Bridges: Healthcare Alliance for Tobacco Dependence Treatment and Pfizer Independent Grants for Learning and Change.

PROVENANCE AND PEER REVIEW

Not commissioned; externally peer reviewed. 